\section{Instagram y política. Mediatización y circulación en los perfiles de Cristina Fernández de Kirchner y Mauricio Macri}

Ana Slimovich ${ }^{(1)}$

\begin{abstract}
Resumen: Desde la sociosemiótica, la teoría de la mediatización de la política y el dispositivo analítico de la circulación contemporánea se indagó en las publicaciones y stories emitidas en Instagram en las cuentas oficiales del ex presidente Mauricio Macri y de la vicepresidenta actual, y ex presidenta, Cristina Fernández de Kirchner, entre marzo y diciembre de 2018. Se concluyó en la configuración de dos estrategias enunciativas distintas que ponen en juego lo político/institucional, lo individual y la mirada del asesor; así como dos tipos de movimientos comunicacionales y cambios de escala en la mediatización.
\end{abstract}

Palabras clave: mediatización - política - Instagram - redes sociales - macrismo - kirchnerismo - circulación.

[Resúmenes en inglés y portugués en la páginas 202-203]

(1) Es Doctora en Ciencias Sociales y Licenciada en Ciencias de la Comunicación por la Universidad de Buenos Aires. Es investigadora asistente del CONICET con sede en el Instituto de Investigaciones Gino Germani. Es docente de Semiótica de redes, Cátedra Mario Carlón (UBA). Dirige el Proyecto de Reconocimiento Institucional -IIGG-: "La circulación hipermediática de lo político en la Argentina”. Forma parte también del UBACYT: "La mediatización en el entretejido de los vínculos sociales". Es premio nacional a la Mejor Tesis Doctoral en Ciencias Sociales (2019) -EUDEBA y FSOC-UBA-, bajo la temática: 2las encrucijadas de las democracias latinoamericanas".

\title{
Introducción
}

En las sociedades actuales hay nuevos tipos de discursos políticos por la crisis en la hegemonía de los medios masivos que lleva ya más de diez años (Verón, 2011 [2007], Carlón y Scolari, 2009), el surgimiento de un nuevo sistema mediático basado en internet y en las redes de la telefonía, y las relaciones generadas entre los dos sistemas de medios: el tradicional y el de las redes sociales (Carlón, 2015). Asimismo, también se ha generado una 
nueva etapa en la mediatización de lo político porque en las últimas décadas se debilitaron los lazos partidarios, se acentuaron los procesos de personalización y personalismo de la política y hubo una fluctuación en las preferencias de los ciudadanos.

Una nueva fase comenzó con la expansión de las redes sociales que implicó la acentuación de procesos políticos y mediáticos que venían del último cuarto de siglo y también la generación de nuevas prácticas, movimientos sociales, tipos, géneros y discursos políticos. En este punto, dado que la política contemporánea está atravesada por nuevas formas de participación ciudadana, se ha llamado a este tipo de democracia, "continua" (Cheresky, 2015, 2019), porque la legitimidad de las decisiones de los políticos está en juego de manera permanente. Las democracias contemporáneas se caracterizan por nuevos modos del discurso político y de participación ciudadana: por procesos de debate entre pares, movilizaciones sociales en el espacio público de internet y un proceso de expansión de la ciudadanía.

En este artículo se analizarán los discursos de las cuentas oficiales de Instagram del expresidente argentino Mauricio Macri y de la vicepresidenta y expresidenta, Cristina Fernández de Kirchner. Se tomarán en cuenta los emitidos desde la apertura de las sesiones legislativas el 1 de marzo de 2018 hasta el 31 de diciembre de ese año. Se analizarán tanto las publicaciones como las stories. Se apunta a indagar tanto en la mediatización construida desde Instagram como en los procesos de circulación de los discursos. Por un lado, en el artículo se enfocará en un análisis del tipo de argumentación digital, el tipo de operación y la puesta en escena de la mixtura entre lo público y lo privado. Por otro lado, dado que las publicaciones que surgen desde la red social de un internauta gobernante o político son el inicio de un proceso de circulación hipermediática del discurso (Carlón, 2015) y de interacción entre pares desconocidos, se indagará en los modos de interpelación al internauta ciudadano, así como en los modos de construcción de canales institucionales para el debate en Instagram. En la primera parte del artículo se precisará el marco metodológico elegido para la realización del trabajo. Luego se detallarán los fundamentos teóricos de la investigación. Se indagará en los modos de conceptualizar las discursividades políticas en las redes sociales y en el cruce con los medios masivos. Se analizarán los rasgos históricos de las discursividades de Fernández de Kirchner y Macri. En la tercera sección se reflexionará sobre los modos de emergencia de las discursividades políticas en Instagram en otros países. Más adelante se presentarán los resultados del análisis en los dos políticos. En la sección sexta se esbozarán las discusiones. Por último, se presentarán algunas consideraciones finales sobre el recorrido realizado.

\section{Metodología}

Este trabajo se inscribe en la socio-semiótica como campo de abordaje de la dimensión significante de los fenómenos sociales, tal como fue sistematizada por Eliseo Verón (1987a). Como el objetivo de esta investigación está vinculado con analizar discursos políticos emplazados en una red social mediática, se articulará el tradicional análisis de la semiótica de medios masivos (el análisis de la enunciación, de las condiciones de producción y reconocimiento, de dispositivos y medios), con la teoría de la mediatización de lo político 
veroniana (1987b, 1998 [1995], 2001, 1986) y el herramental metodológico del análisis de la circulación hipermediática contemporánea (Verón, 1987; Carlón, 2015, 2016a; 2016b), que da cuenta de una circulación más compleja entre los medios masivos y los nuevos medios. Se concibe entonces a los discursos como configuraciones espacio-temporales de sentido, que tienen un anclaje social y que poseen restricciones en su generación y en su lectura (Verón, 1987a). Se considera que el momento contemporáneo está atravesado por relaciones convergentes y divergentes en el mundo de la política. En este sentido, para indagar en el proceso actual de circulación de lo político, el punto de partida es determinar y describir el discurso de origen (Carlón, 2015) que, en este caso, se concentra en las publicaciones de Macri y Fernández de Kirchner en Instagram.

La unidad de análisis de este trabajo está conformada por las publicaciones y stories en la cuenta de Instagram de Macri y de Fernández de Kirchner, en el período de marzo a diciembre de 2018, así como los movimientos comunicacionales posteriores. El análisis se concentra en una comparación entre los discursos políticos de Macri y de Fernández de Kirchner con origen en Instagram. Para el armado del corpus y dado que la pregunta de investigación está vinculada tanto al modo de enunciar de cada político/a como a la circulación de sus discursos con origen en Instagram, se seleccionaron las dos publicaciones con mayor cantidad de megusteos y comentarios de cada mes, en cada cuenta. Se consideraron solamente las que generaron movimientos comunicacionales posteriores: "ascendentes y descendentes" (Carlón, 2015). En otras palabras, se tomaron en cuenta para el análisis las publicaciones y stories que generaron no solamente comentarios de los internautas, sino repercusiones en los medios masivos y movimientos al interior de las redes sociales.

Dentro de las redes sociales, Instagram ha crecido en la cantidad de usuarios en los últimos años y específicamente ha concentrado especialmente tanto discursos de los políticos como discursos políticos de internautas desconocidos. Según la encuesta de Consumos Culturales ya en 2017 se había posicionado como la segunda red social más utilizada por los argentinos -el 27, 3 \% poseían una cuenta en Instagram. La más utilizada seguía siendo Facebook con el 64,4 \%-. Asimismo, otros autores establecen que Instagram es la red social que recibe la mayor cantidad de migrantes de Facebook y la que contiene a los sectores más jóvenes (Amadeo, 2018). Por otro lado, la elección del análisis de Instagram en este trabajo se sustenta también en que se trata de la red social en la cual se ha producido mayor cantidad de debates políticos en los últimos dos años puesto que no sólo los gobernantes y políticos han abiertos sus cuentas y las utilizan diariamente y como parte de la campaña, sino que generan publicaciones que se visualizan únicamente por esta red social, como fue el caso del Instagram en vivo que realizó el presidente Macri en julio de 2018.

Se tendrá en cuenta que en la sociedad actual, hipermediática contemporánea, por el contrario, conviven el sistema de los medios masivos y el sistema de las redes sociales: los actores individuales generan colectivos y las direcciones comunicacionales, además de la histórica "descendente" -desde los medios masivos hacia los actores individuales-, se incorporan la "horizontal" -entre enunciadores de igual estatuto- y la "ascendente": la que surge desde las redes sociales y genera repercusiones, e incluso colectivos, que surgen desde internautas desconocidos y alcanzan los medios masivos (Carlón, 2015).

El objetivo de este trabajo apunta a la comparación del tipo de discursividad que surge desde la institución política en Instagram en el caso de cada uno de los políticos, así como 
en la circulación hipermediática que generan: las repercusiones en internautas ciudadanos y los ascensos y descensos en la relación con los medios tradicionales y con otras redes sociales. Las preguntas de investigación son: ¿Cuáles son los discursos con origen en las cuentas oficiales de Macri y Fernández de Kirchner en la red social Instagram que generaron mayor cantidad de movimientos comunicacionales? ¿Cómo es su enunciación y su circulación hipermediática?

\section{Marco teórico y revisión de la literatura}

\section{Discurso político contemporáneo}

El mundo de lo política contemporánea está mediatizado puesto que los modos de hacer de la política se realizan a través de los medios de comunicación masiva y de los medios con base en internet, tanto en relación a la producción como a la recepción. El proceso de imbricación del campo de lo político con el campo mediático se ha ido acelerando con el tiempo. Uno de los investigadores que más ha estudiado este proceso ha sido el semiólogo Eliseo Verón y ha distinguido dos momentos. El teórico diferencia una sociedad mediática de una mediatizada. A la primera la define como aquella en la cual "los medios se instalan: se considera que estos representan sus mil facetas, constituyen una clase de espejo (más o menos deformante poco importa) donde la sociedad industrial se refleja y se comunica" (Verón, 2001: 14). O sea, existe una frontera entre lo real social y la representación que realizan los medios de comunicación. En la mediatizada, por el contrario, "el funcionamiento de las instituciones, de las prácticas, de los conflictos, de la cultura, comienza a estructurarse en relación directa con la existencia de los medios" (p. 15); y se borra el límite entre "lo real" y "sus representaciones". Los fenómenos de la sociedad adquieren formas específicas en virtud de la existencia de los medios.

En la era contemporánea, siguiendo a Carlón (2015) estamos en una "sociedad hipermediatizada", atravesada por procesos de circulación intermediáticos e intersistémicos: ascendentes y horizontales, además de los descendentes, característicos de la era de los medios masivos. Según el autor se trata de procesos de interacción no sólo entre distintos medios, sino entre el sistema de medios masivos y el de las redes sociales y telefonía en los cuales participan internautas e instituciones. Las prácticas políticas, por ende, se ven influidas por estas nuevas condiciones de la circulación de los discursos.

En la sociedad hipermediatizada contemporánea hay nuevos tipos de relación entre gobernantes y gobernados.

Los internautas disponen, en las redes sociales, de verdaderos medios de comunicación y, por consiguiente, de espacios propios de intervención en la vida social. Es en estos espacios, que no son neutros, que realizan como sujetos activos múltiples operaciones: opinan, comparten y se apropian de contenidos que les interesan (provenientes de los medios masivos, de la historia del arte y la fotografía, etcétera) (Carlón, 2016a, p. 45). 
Los medios masivos de comunicación siguen realizando algunos de los relatos y de las argumentaciones políticas que están en el centro de la vida social; no obstante, se adicionaron las voces desintermediadas de los propios políticos y las ciudadanas en el espacio público que se amplía con los medios con base en internet.

En esta investigación se sostiene que la fase contemporánea de mediatización de lo político supone, por un lado, operaciones de desintermediación en la relación entre los líderes políticos y los ciudadanos puesto que los políticos se contactan con sus destinatarios a través de las redes sociales sin intermediarios periodistas. Por otro lado, se generan operaciones de interfaz de los discursos informativos/periodísticos y políticos en el espacio de las redes sociales y los fragmentos de los noticieros, programas políticos de opinión, prensa gráfica vuelven a emerger en el espacio público mediatizado de los políticos en Facebook, Twitter, Instagram, Pinterest, Snapchat.

En este punto cabe observar que en la sociedad contemporánea se ampliaron los enunciadores políticos y los tipos de discursos puesto que se ha producido un ensanchamiento del espacio público. Se puso de manifiesto que el público replicante en Internet no solo está constituido por militantes o pertenecientes a partidos políticos, sino que también se ha agrandado. "Se han incorporado a la esfera pública ciudadanos que no habían tenido un rol activo en las campañas políticas que se desarrollaban únicamente en medios masivos de comunicación" (Slimovich, 2014, p. 15), así como se han sumado trolls y bots en el entramado discursivo político contemporáneo, -sin que sea posible determinar con anterioridad los efectos de sus intervenciones en las campañas-. En este sentido, los internautas "se encuentran empoderados en su capacidad de producción y consumo informativo, cuestionando el lugar tradicional de los medios en la construcción de agenda" (Mitchelstein, Leiva Giuliano, Boczkowski, 2018, p. 169).

El proceso de mediatización de la política, ha generado en las últimas décadas un pasaje desde una democracia de partidos hacia una de audiencias (Manin, 1998), puesto que se debilitaron los lazos partidarios, se generó un proceso de personalización de la política y hubo una variación en las preferencias electorales de los ciudadanos (Castells, 2009; García Beaudoux, V., D’Adamo, O. y Slavinsky, G., 2005; Novaro, 1994). Este proceso de debilitamiento de las grandes identidades partidarias comenzó en la década del 90 y la expansión de las redes sociales permitió un nuevo giro hacia la acentuación de la personalización y el proceso del personalismo de la política que se detallará a continuación. En sus estudios sobre las discursividades digitales en España, Dader (2003) vislumbra una democracia replicante, puesto que una parte del público se suma al diálogo político mediante la interpelación que le permiten los nuevos medios. Es decir, se alude a una multiplicación de emisores de contenidos políticos digitales. Por su parte, Beas (2011) indaga en la campaña de Barack Obama en Estados Unidos y afirma que la esfera pública se renueva al incorporar activamente al ciudadano en la vida política a través de plataformas digitales. Así, se hace mención a una co-construcción del storytelling político ( $D^{\prime}$ Adamo y García Beaudoux, 2013) por parte de los candidatos y de los ciudadanos.

Una de las características fundamentales de la política ya en la era de la sociedad mediatizada (Verón, 1986) es "la personalización de la campaña política" en los medios. Es decir, la centralización en la cobertura mediática de la vida política en determinadas figuras o líderes políticos. Al mismo tiempo, se genera desde hace décadas en las democracias 
occidentales de la presencia de personalidades carismáticas que concentran las lealtades partidarias; y a este proceso se lo denominó "el personalismo del proceso político" (Slimovich, 2016). En el período de la política contemporánea se registra una acentuación de estos dos procesos, esta profundización se puede considerar una consecuencia tanto de los nuevos espacios digitales como de las estrategias actuales de los actores políticos (Van Aelst, Scheafer y Stanyer, 2011).

Cabe especificar que, si bien se trata de una tendencia que lleva décadas en la democracia occidental y en nuestro país, que está en paralelo al proceso de espectacularización y mediatización de la política, los discursos del $\mathrm{PRO}^{1}$ en las redes sociales, a través de la difusión de los timbreos y de la referencia a aspectos de la vida privada e íntima tanto de Macri como del resto de los políticos de la coalición, son especialmente marcados en este aspecto desde el inicio de la ruta digital en Facebook y Twitter.

\section{Personalización de la política}

En el momento actual el vínculo entre representantes y representados está basado en la proximidad, así lo sostiene Annunziata (2012). Se retoma así el concepto de "legitimidad de proximidad" de Rosanvallon (2009) que implica la atención a lo individual/particular. Supone que los ciudadanos demandan a los gobernantes que sus experiencias de vida, sus puntos de vista y sus demandas sean escuchadas. En este punto la autora considera que en el momento actual se da un tipo de vínculo representativo "que se estructura sobre la base de una identificación anticarismática entre representantes y representados, se manifiesta en la presentación de los primeros como personas comunes" (Annunziata, Ariza y March, 2018, p.62). Los políticos aparecen como hombres capaces de compartir las experiencias singulares de los ciudadanos, emergen desde lo mundano, desde su capacidad "de comprender sus vivencias cotidianas, de prestarles atención y de escuchar sus inquietudes y necesidades" (Annunziata, 2012, p. 73). Esta modalidad, incluye rasgos de los anteriores, como la mediatización y el rol creciente de los liderazgos frente a los partidos; no obstante, al mismo tiempo implica un rechazo a los políticos que están alejados de la ciudadanía. Los candidatos se presentan entonces como "hombres comunes" y - "como posicionados cerca de ellos"-; por consiguiente, disimulan la diferencia representativa (Annunziata et al, 2018) realiza un análisis de las publicaciones en Facebook, Twitter e Instagram en 2018 de gobernantes macristas y concluye que predomina el contenido considera que es íntimo -"se transmite un mensaje que muestra aspectos de la vida privada, familiar, de los dirigentes" (p. 76); y el ciudadano -se transmite un mensaje que tiene a los ciudadanos comunes como protagonistas (ídem)- por sobre el institucional -"se transmite un mensaje de gestión” (ídem) -y por sobre el político- "aquel en el que se transmite valores o toma de posición significativos para la identidad del espacio político al que pertenecen los dirigentes (ídem)"”. 


\section{Redes sociales macristas}

La estrategia de proximidad no está acotada a un solo partido dado que es un rasgo de la política contemporánea que está atravesada por relaciones entre medios masivos y redes sociales.

No obstante, en estudios nuestros anteriores sobre la circulación hipermediática de los discursos macristas se ha descripto cómo el PRO -y luego Cambiemos- puso énfasis en la comunicación política a través de las redes sociales y se ha indagado en cómo estos espacios digitales acentúan el proceso de personalización de la política y la reposición de los aspectos íntimos/privados de los políticos (Slimovich, 2012, 2018b). Por otro lado, se ha indagado en las publicaciones con origen en las cuentas en redes sociales de los dirigentes macristas y se ha concluido que predomina en ellas la mixtura de lo público/ privado y una puesta en escena de lo íntimo, tanto en lo que respecta al gobernante/ candidato como del ciudadano desde que se generó la apertura de los espacios digitales en $2009 / 2010$.

En el inicio de las redes sociales de Macri se observa que hay una mixtura entre la fórmula eslogan, los globos y la buena onda (Vommaro, Morresi, Belloti, 2015), y el relato de gestión. El componente lúdico está presente en el discurso electoral en las redes sociales de Macri desde el inicio. En este sentido, se ha observado que hay una "teatralización de la vida privada" (Slimovich, 2012): una puesta en escena de la subjetividad en su muro de Facebook y en los tuits, un proceso que destaca su rol como hombre mundano, en línea con rasgos de los procesos de personalización y personalismo de la política contemporánea. La materialización de esta operación se produce con videos que contienen retazos de timbreos realizados por candidatos/gobernantes; visitas a los hogares y locales de ciudadanos, actos de gestión, llamadas telefónicas, relatos sobre la vida privada, fotos del "álbum familiar", textos lingüísticos sobre acontecimientos político-mediáticos, entre otros. El componente pasional está presente en el discurso en las redes sociales de Macri desde el inicio, tanto en los momentos de campaña como en los de comunicación de gobierno, tanto en su posición de jefe de gobierno de la ciudad de Buenos Aires como en el de presidente de la nación.

Se apunta a la provocación de emociones en los internautas, tales como la conmoción frente al embarazo de su mujer en 2011, o a la ternura frente a los audios de WhatsApp de su hija Antonia gritándole su amor publicados en el muro de Facebook en 2015, días antes de la elección que lo consagró presidente; así como también la foto del presidente en el jardín de su hija, en Instagram en julio de 2017, y la aclaración de que había sido Antonia la que había pedido la presencia de su padre; así como la compasión por los ciudadanos que pasaron por muchas cosas difíciles en su vida y se las cuentan al presidente en su propia casa en un video que reproduce un fragmento de un timbreo (Slimovich, 2017b, p. 5).

Se ha especificado que este tipo de publicaciones en las cuales Macri narra su historia familia, así como la historia de vida de los ciudadanos a través de los retazos de timbreos y 
visitas en Instagram, Facebook y Twitter convocan a un tipo de internauta específico que se ha denominado: "internauta seguidor descontracturado" (Slimovich, 2017a, p. 35). Asimismo, también se ha descripto que Macri puso en escena en las redes sociales estrategias de interrelación mediática en 2011 que luego intensificó en la campaña de 2015 y como presidente entre 2015 y 2019. Se trató de la implementación de publicaciones en una red social que contenían operaciones de emulación de lógicas de los medios masivos y operaciones de apropiación de contenidos televisivos, de prensa gráfica o radio, así como concentró discursividades ligadas al mundo de lo privado y también a lo público/ institucional, que ponen en juego argumentos que apuntan a lo racional y también a lo pasional, en forma de brevedades (Slimovich, 2012, 2016).

Se ha concluido en que la circulación hipermediática de las publicaciones de los y las dirigentes macristas, sus repercusiones en los medios masivos y al interior de las propias redes sociales -la articulación con hashtags, la articulación con movimientos sociales en las redes-, no está necesariamente ligada al tipo de publicación (público/privado), ni al tipo de materialidad puesta en juego (video, foto, texto lingüístico), ni al tipo de destinatario interpelado, ni al tipo de duración de la publicación (story, publicación permanente) que emite el candidato/gobernante sino que suele estar vinculado con la acción de los "internautas opositores macristas" (Slimovich, 2018a) que inician un movimiento en contra de la publicación y generan repercusiones al interior de los espacios digitales y reacciones de los medios masivos (Slimovich, 2019).

El proceso de presentación del candidato como hombre común es un rasgo de la política contemporánea, no es específico de Macri ni de la mediatización de la política en las redes sociales. No obstante, en el caso del presidente argentino emergen formas específicas desde la apertura de los espacios digitales, en el mismo momento en el que el resto de los políticos y políticas argentinos y argentinas sólo producían discursividades ligadas a lo público, como es el caso de Cristina Fernández de Kirchner.

\section{Redes sociales kirchneristas}

En el caso de Fernández de Kirchner los discursos políticos en Facebook y Twitter (así como los dados en los medios tradicionales) se caracterizaron desde el inicio por "una fuerte -aunque heterogénea-inscripción al peronismo y, además, por una revalorización de la discusión política" (Gindin, 2018:7). En este punto las lógicas de lo privado y de lo íntimo convivían con la interpelación al adversario político y por consiguiente se puede pensar en una lógica de la "proximidad partidaria" (ídem).

En las redes sociales de los líderes kirchneristas en general, y de Cristina Fernández de Kirchner en particular, se evidencia la existencia de "micro-argumentaciones lógicas" y también "pasionales", son discursos propios de las redes sociales, pildorizados de sentidos y que atraviesan distintos medios y redes (Slimovich, 2012, 2018b). Al igual que en el caso de los políticos macristas, se registran desde la apertura de los espacios digitales hasta la actualidad. Uno de los modos de emergencia de los "micro-entimemas" y "micro-ejemplos" en las redes de Fernández de Kirchner está vinculado a operaciones que suponen interfaces 
político-informativas. En las sociedades en las cuales sólo existían medios masivos de comunicación, la sociedad mediática y mediatizada, se daban procesos de "interfaz entre lo político y lo informativo" (Verón, 2001): los discursos de los políticos argentinos estaban insertos en la macro-enunciación informativa de la emisión televisiva-noticiero o programas políticos de opinión, entre otros -y de la prensa gráfica y radio- con su instancia en off, su música, su resumen, la palabra de los conductores, etc. En las sociedades actuales, se generan espacios de interrelación políticos-ciudadanos que no poseen a los periodistas como intermediarios. No obstante, se ha especificado que por primera vez en la mediatización de la política surgen "interfaces político-informativas" en las redes sociales. Esto es, los discursos políticos en las redes sociales están en relación con las lógicas y contenidos de los medios masivos informativos (Slimovich, 2016).

Específicamente en el caso de Fernández de Kirchner, tanto en Facebook y en Twitter como en Instagram, se registran interfaces en las publicaciones y stories con "apropiación, intervención y montaje" (Carlón, 2014), que reponen operaciones que vienen del mundo de los medios tradicionales y del campo del arte. Estas operaciones en el caso de Fernández de Kirchner se concentran en la reposición de "motivos vinculados a lo público", al rol institucional -cuando es presidenta- y también a su posición como opositora al gobierno macrista entre 2015 y 2019. En la campaña de 2017 es uno de los momentos en los cuales la puesta en escena del cuerpo político se mixtura más con lo íntimo y lo privado.

En el inicio de las discursividades digitales de Cristina Fernández de Kirchner, se registra una operación de "emulación del discurso informativo-periodístico" (Slimovich, 2012). Es decir, se enuncia en Facebook y Twitter imitando las formas de una gacetilla de prensa. En estas publicaciones hay citas de los actores de la noticia, cifras que respaldan los dichos, y finalmente, un rasgo fundamental del estilo periodístico del siglo XX: la conformación del enunciador como un agente de la información (Steimberg, 1993a [1982]). Incluso, hay fragmentos que ubican a la entonces presidenta como sujeto del enunciado, sin asumir la primera persona de la enunciación. Esta modalidad de la interfaz fue propia de ese momento originario de los discursos políticos en las redes sociales. Esta operación muta cuando a fines de 2015 deja el cargo de presidenta y pasa a constituir la oposición. No se registra esta operación en las cuentas en las redes sociales de Macri en ningún momento de su historia digital.

Dado que ya se ha realizado un relevamiento de los modos históricos de mediatización de los discursos políticos en Facebook y Twitter de los dos políticos que se analizarán en este trabajo, en la sección siguiente se realizará la descripción del modo de producción y circulación de los discursos políticos en Instagram.

\section{La política en Instagram}

Las cuentas de Instagram de Macri y Fernández de Kirchner fueron abiertas en 2011 y 2013, respectivamente. No obstante, la primera campaña política en la que la mayoría de los candidatos argentinos tenían una cuenta en esta red social fue recién en 2017, y es a partir de ese momento que la plataforma ocupa un lugar relevante en la difusión de 
discursos de gobernantes y candidatos. Las dos cuentas poseen más de un millón de seguidores, si bien Macri tuvo durante la presidencia una utilización mucho más frecuente que la de Fernández de Kirchner y la vicepresidenta aumentó mucho la cantidad de internautas que la siguen desde su asunción en diciembre 2019.

En octubre de 2010 se lanza la versión definitiva de Instagram (una fusión de Instant y Telegram) y al poco tiempo "alcanza los 10.000 usuarios, más de 100.000 en la primera semana" (Gallardo y Enguix, 2016: 61). La compra Facebook en 2012. Se trata de una red social en la cual predominan las fotografías lo cual genera que muchos estudios sobre esta plataforma se centren en el estudio de la relación de la imagen con el texto, así como del tipo de imagen que predominan.

Carlón (2016b) estudia la fotografía contemporánea y explica que se han modificado las condiciones de circulación dado que hoy está inscripta en el campo de la interactividad; y, está asimismo atravesada por un presente compartido. En este sentido, el teórico hace alusión a una crisis actual en la relación histórica entre el pasado, el presente y el futuro. Se refiere al momento contemporáneo como una época en la cual el presente ha emergido con fuerza y se ha articulado con los nuevos modos de la mediatización. Lo contemporáneo implica la "emergencia de un nuevo régimen de historicidad: el presentismo" (Carlón, 2018, p. 109). "Cada narciso administra hoy su propio medio de comunicación" (p. 110), por consiguiente, se da un nuevo tipo de relación en el momento actual entre el individuo y las redes sociales, que es pertinente plantear dado el objetivo de estudio de este trabajo. Siguiendo a Carlón se generaron nuevos modos de producción de contenidos mediáticos, nuevos modos de la circulación y nuevos tipos de enunciadores profesionales y amateurs. Los internautas comunes, hoy poseen con las redes sociales como Instagram, la capacidad de capturar y editar imágenes y subirlas al "espacio público ensanchado". Cuando lo hacen pueden recibir comentarios y réplicas de otros internautas casi en instantáneo. Son fotografías, las de Instagram, que contienen una "indicialidad débil" (p. 49).

Cabe determinar entonces que los "internautas ciudadanos" saben que las imágenes que comparten en sus cuentas de Instagram Macri y Fernández de Kirchner, que se analizan en esta investigación, y que apuntan al registro de un acontecimiento, pueden ser alteradas o modificadas tanto por parte de los enunciadores políticos como luego en los movimientos comunicacionales posteriores.

En relación a la fotografía contemporánea, se ha insistido en concluir que uno de los tipos más comunes es la selfie, grupal o individual. Para Carlón, las selfies, contienen un rasgo moderno puesto que constituyen el "registro de un momento" y se encuentran más cerca del "está allí ahora" (Carlón, 2016b), atravesado por la duda propia del carácter actual de la imagen, que se ha mencionado con anterioridad. Asimismo, contienen un rasgo propio de la época porque muchas veces son capturadas por enunciadores amateurs en un momento de su vida íntima y privada. En el caso de los políticos pueden ilustrar un acontecimiento público o uno del orden de lo privado e íntimo que acerque al político a un rasgo de lo mundano. No obstante, se sostiene como hipótesis en esta investigación que la selfie emitida desde la cuenta del político en Instagram tensiona la distancia entre la enunciación del asesor y la del político que ha caracterizado los discursos de los políticos en las redes sociales desde sus inicios en la segunda década de este siglo (Slimovich, 2016). 
Si se revisan los estudios de la fotografía en Instagram debemos recalcar que uno de los autores pioneros en este estudio es Manovich (2017), quien analiza imágenes actuales de distintos internautas de distintas ciudades del mundo y diferencia, en paralelo a la distinción que se mencionó con anterioridad, entre amateur o casual: fotografía de Instagram que "privilegia el contenido frente a la forma" y fotografía "profesional o competitiva" que atiende a la calidad y busca tener likes y followers. El autor acuña el término "instagramismo" para dar cuenta de la identidad cultural contemporánea que favorece la forma y explica que con Instagram se pueden crear perfiles únicos a través de las fotografías. Los estudios específicos sobre nuestro objeto de estudio, el uso de los políticos de Instagram, se encuentran en un estado incipiente y los podemos clasificar en cuatro tipos. En primer lugar, los que realizan un análisis de contenido de las publicaciones de los políticos en Instagram en un determinado período (electoral o no electoral); y de este modo, concluyen en determinar el modo de comunicar de ese líder en esta red social. Es el caso de la investigación de Jung et al (2017) sobre las cuentas de Instagram de los políticos de Singapur. En algunos casos utilizan herramientas de monitorización y métrica, como Social Elephant, y estudian "la marca personal de un candidato", como en el caso de Verón y Pallarés (2017) en su estudio sobre el perfil de Instagram del líder del partido político español Ciudadanos: Albert Rivera. En un plano paralelo, Lopez-Rabadán y Domenech-Frabregat (2018) producen un análisis del uso de los políticos españoles en Instagram con 10 indicadores del grado de espectacularización en sus cuentas oficiales, en uno de los momentos con mayor intensidad del proceso independentista de Cataluña (2017-2018).

En segundo lugar, los que también tratar de capturar el estilo del político en Instagram, no obstante, utilizan la metodología de análisis de contenido y le adicionan análisis cualitativo. Es el caso de Selva-Ruiz y Caro-Castaño (2017) que estudian el uso de Instagram por parte de los diputados españoles, en el período posterior a la elección de julio de 2016. Así, los teóricos que se encuadran en este grupo tienden a indagar el grado de humanización del político o de interacción de las cuentas de los líderes con los ciudadanos, a través del uso de herramientas como la mención, el hashtag, entre otros. Dentro de este tipo de estudios, también se registran los que realizan una indagación en recepción (Verón, 1987a) de las cuentas de los políticos en Instagram, y así se centran en las repercusiones en los internautas y suelen estar también ligadas a investigar la personalización y humanización de la figura del líder en esta red social. Es el caso de Olof Larsson (2019) quien investiga si el contenido publicado por los políticos noruegos -y por los partidosen Instagram vinculado a la personalización "tiene éxito en términos de recepción, en "megusteos" y "comentarios" en la plataforma" (p. 1097).

En tercer lugar, los que realizan un estudio del tipo de imagen fotográfica utilizada por el político en la red social, en algunos casos suman la relación entre la fotografía y el texto que la acompaña y concluyen en tipologías de "tipos de imágenes políticas" en Instagram. Es el caso de Quevedo-Redondo y Portales-Oliva (2017), quienes -con análisis de contenido y métodos cualitativos- indagan en las fotografías y videos realizados en Instagram por los candidatos a la presidencia española en 2015 y su relación con el texto lingüístico. Concluyen en comprobar la apuesta por la humanización de la figura de los políticos en Instagram en tiempos de campaña y en identificar "elementos distintivos de la cultura 
de la fama que dan forma a la dicotomía entre lo extraordinario (la actividad política) y lo ordinario (la vida privada)" (p. 917).Así, se alude a la existencia de un "proceso de celebrificación que persigue activar la empatía de un target joven con un estilo más ligero e informal que el acostumbrado en medios tradicionales" (p. 918). También es el caso de Mohamed (2019) quien se centra en determinar la construcción de narrativa política en las fotografías utilizadas por los candidatos a Primer Ministro de Malasia en Instagram, en mayo de 2018. El teórico concluyó en mostrar que los candidatos alternaban entre imágenes personales y "políticas". En este sentido, organiza una clasificación de seis tipos de historias políticas narradas en imágenes. Por un lado, las actividades de campaña, los materiales producidos para la elección, y las imágenes del político trabajando. Estas tres primeras constituyen el tipo de historia "política-pública" y para el caso de Malasia se concluye que los candidatos utilizan más este tipo de fotografía en Instagram. Por otro lado, el autor refiere a las historias privadas y personales: imágenes familiares, actividades personales e imágenes "del pasado que representan cierta memoria o experiencia que es relevante en la vida actual del candidato" (p.364).

Por último, los que comparan contenidos de las cuentas de los políticos en Instagram con lo producido para otras redes sociales o medios tradicionales, en la misma campaña. Apuntan a determinar las diferencias de uso de las redes sociales entre sí, Facebook, Twitter, Instagram, Snapchat, WhatsApp -y también con la comunicación política en medios tradicionales. Es el caso de Bossetta (2018) quien realiza un análisis comparativo entre las publicaciones realizadas durante la campaña electoral estadounidense de 2016 en 4 plataformas: Facebook, Twitter, Instagram y Snapchat. Apunta a mostrar que la estrategia política contemporánea está influida por los algoritmos y reglas propias de cada espacio digital en el que se inserta.

Por el contrario, en esta investigación se realizará una indagación de los discursos originados en el Instagram de Macri y Cristina Fernández de Kirchner durante 2018 -año no electoral en Argentina, se analizará la enunciación de esos discursos políticos mediatizados (Verón, 1986) y luego la circulación hipermediática. De este modo, a diferencia de los estudios anteriores, se pondrá en relación el discurso producido en Instagram, tanto con sus condiciones de producción (Verón, 1987a), que incluyen también los modos de comunicación en otras redes sociales y medios masivos; así como con los movimientos comunicacionales posteriores. Se tendrá en cuenta la perspectiva de la circulación hipermediática contemporánea (Carlón, 2015, 2016a, 2016b), por consiguiente, se tomarán las publicaciones en las cuentas de Instagram de los políticos como "discursos de origen" de movimientos comunicacionales posteriores.

\section{Enunciación institucional/extrainstitucional}

Selva-Ruiz y Caro-Castaño (2017) indagan en la cuenta en Instagram de Mariano Rajoy en el momento en que era presidente del gobierno español (2017) y concluyen que lo habitual es que en sus publicaciones se lo visualice visitando instalaciones públicas, en entrevistas en los medios o en el Congreso y que no haya imágenes que apuesten a la 
humanización del político. No obstante, sí se registran fotografías del presidente que dan cuenta del tiempo privado, como un vídeo caminando por las proximidades del río Miño. Concluyen que "tanto el punto de vista elegido para la cámara, como el uso del plano fijo y la lejanía del político en la imagen, son decisiones que enfatizan el carácter profesional de la pieza" (p. 908). En este punto se observa la predominancia en Instagram de una mirada que se podría denominar "profesional".

Por otro lado, en un estudio realizado sobre la cuenta en Instagram del presidente del partido político español Ciudadanos, Albert Rivera, Verón y Pallarés (2017) determinan que se apunta a mostrar una imagen más personal y cercana con los ciudadanos a través de las fotografías publicadas que responden a espacios privados. De modo paralelo a lo que se apuntó sobre Rajoy, también en el caso de Rivera, las fotografías ponen en escena el enunciador asesor dado que uno de los modos de presentación de las imágenes es a través del ángulo contrapicado que "se emplea principalmente como herramienta para exaltar la imagen de Rivera y potenciar la percepción del político como líder de su partido" (Verón y Pallares, 2017, p. 10).

En definitiva, es posible determinar, luego del análisis que se ha realizado, que ese tipo de edición y recursos aplicados a la fotografía de Rivera y de Rajoy, incluso en aquellos casos en los que las imágenes remiten a aspectos de lo íntimo y de lo privado del político, ponen en primer plano la enunciación del asesor. En el análisis de las publicaciones de los políticos argentinos en este trabajo se apuntará a determinar qué tipo de enunciación predomina.

\section{Resultados}

La cuenta de Instagram de Fernández de Kirchner posee como foto de perfil una en la que se la ve a ella riendo y detrás a su marido, el expresidente Néstor Kirchner detrás. La imagen es la misma que posee en Facebook y en Twitter desde el 2010, momento del fallecimiento de él. Al igual que lo que se especifica con líderes políticos de otros países, tiene más de un millón de seguidores -como se ha detallado-, no obstante, sólo sigue a 69 usuarios. Macri también posee la misma foto que en las otras redes sociales y es una en la que sólo se le ve la cara. En un plano paralelo al manejo de la cuenta que especificamos con la senadora, el presidente también posee mucha diferencia entre los seguidores, tiene la misma cantidad de seguidores, y los seguidos, que son sólo $128^{3}$.

En el análisis de las publicaciones y stories de la cuenta de instagram de Fernández de Kirchner durante el 2018 se observa la aparición de "micro-argumentaciones lógicas multimediáticas" (Slimovich, 2012). Es decir, a través de fotos, videos y texto lingüístico la actual vicepresidenta argumenta de modo breve y pildorizado, dando "pruebas lógicas" (Barthes, 1985) acerca de porqué Macri estaba gobernando de un modo que perjudicaba a la ciudadanía y generando aumentos de tarifas innecesarios, empobrecimiento de la población, enriquecimiento de ciertos sectores empresariales afines, persecución judicial a su persona, entre otros. El modo de despliegue de la argumentación es a través del texto lingüístico, una invariante en las stories de la senadora durante el 2018, y constituye, como se desarrollará 
a continuación, una de las principales diferencias con las stories presidenciales, que son principalmente relatos audiovisuales.

Una de las publicaciones que formó parte de la muestra que se ha analizado es el caso de ocho stories publicadas el 3 de julio de 2018 en las cuales se construye -en la serie- un "micro-entimema" (Slimovich, 2012) una comparación entre las tarifas actuales que abonan los ciudadanos, las que pagaban cuando gobernaba Fernández de Kirchner, -mucho menores-, y el relato macrista acerca del aumento y la existencia de subsidios (ver la Imagen 1, Fernández de Kirchner, 2018a). Asimismo, y en línea con la estrategia comunicacional desplegada en otras redes sociales, se provee el enlace a otra red social -en este caso, Facebook- en el que están las pruebas argumentativas. Asimismo, también se interpela a un internauta específico, el que se ha denominado "internauta militante" (Slimovich, 2012), a sumarse a la campaña en contra del tarifazo con el hashtag \#BastaDeTarifazos. Es decir, a que produzca él mismo argumentación política en forma de brevedades en las redes sociales.

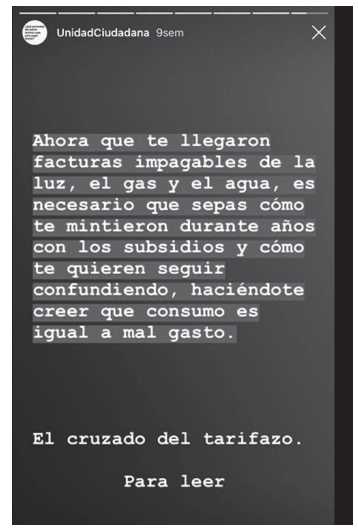

Figura 1. Story emitida desde la cuenta de Instagram de Cristina Fernández de Kirchner. Fuente: Instagram.

Otras de las publicaciones analizadas fueron las referidas a los motivos temáticos (Segre, 1994) de la citación a la justicia de Fernández de Kirchner. En forma de publicación generaron comentarios a favor y en contra, marcando la conformación de un colectivo de "internautas seguidores" y de "internautas opositores" al kirchnerismo. En forma de story aparecen bajo el pedido por parte dela ex presidenta a los "internautas seguidores" para que no se movilicen cuando ella es citada a declarar. Es decir, es un pedido a que los militantes se queden en sus casas y no se movilicen en señal de apoyo. Se trata de stories que no poseen sonido y muchas veces tampoco fotografías, sino que predomina la emergencia de texto lingüístico. Se desarrollan micro-argumentaciones que apuntan a vincular los momentos en los que la expresidenta recibe citaciones judiciales con las crisis económicas y ajustes del gobierno de Macri. De este modo apunta a que el internauta complete la argumentación 
con la inferencia de que se la cita a la justicia como un modo de "distracción" de la situación económica que enfrentó el país bajo el gobierno macrista.

Si se retoma la pregunta de qué tipo de motivos temáticos emergen -si los vinculados a lo privado o a lo público- en las stories y publicaciones analizadas en Instagram en 2018, se puede determinar que hay predominio de publicaciones vinculadas a lo público en la cuenta de Fernández de Kirchner. Ninguna de las publicaciones ni stories analizadas responden a motivos "de familia", ni "personales" ni de "rememoración del archivo personal", como se ha especificado con anterioridad para el caso de los políticos españoles.

Por otro lado, si se retoma la pregunta por el tipo de mirada puesta en juego en las publicaciones, se puede concluir que hay una enunciación institucional en primera persona, a diferencia de ese primer momento -que se describió con anterioridad- en Facebook y Twitter. El punto de vista desde el cual se interpela a los internautas en Instagram es el de la senadora: se evidencian fotos y fragmentos de sus intervenciones en el congreso, descripciones sobre su pasado como presidenta de la nación, argumentaciones pildorizadas de sentido que retoman relatos macristas que circulan en los medios masivos de comunicación y en las redes sociales para apuntar a desmentirlos y a poner en escena los contra-argumentos. Se interpela a un "internauta ciudadano, sin opción electoral", ni macrista, ni kirchnerista, al que se le otorga pruebas del fracaso de la presidencia de Macri y de la necesidad de una vuelta del kirchnerismo al gobierno nacional. También, hay múltiples fotografías entre las publicaciones que la muestran en compañía de distintos mandatarios y ex mandatarios latinoamericanos.

Incluso cuando aparecen retazos de la vida privada de la expresidenta se la incluye en un entramado que la coloca en su rol de "política", y en menor medida, como "ser humano" o como "mujer". Es el caso de la serie de las stories publicadas el 15 de septiembre, en las cuales, asumiendo la enunciación en primera persona, Fernández de Kirchner cuenta a través de placas con texto lingüístico que le llegó un mensaje de su prima que la hizo emocionarse. Luego, genera una operación de apropiación (Carlón, 2014) de contenidos de otra red social, de WhatsApp, para mostrar la imagen del mensaje de su prima. En este sentido, se evidencia como la argumentación en las stories de Instagram de Fernández de Kirchner se construyen en esa convergencia digital de pildorizaciones de sentido y operaciones de interrelación mediática (ver la Imagen 2, Fernández de Kirchner, 2018b). En el mensaje compartido se puede leer que se relata la historia de empleadas de una marca de ropa que pierden el trabajo porque cierra la fábrica -bajo el gobierno de Macri- y que le regalan una camisa del local con su último sueldo. Fernández de Kirchner incorpora en una story la foto del regalo, les agradece y les promete que "van a volver a tener trabajo, esperanza y sueños".

Asimismo, y si se retoma el dispositivo analítico de circulación hipermediática que es uno de los objetivos que se ha especificado en este trabajo, se puede especificar que estas stories no generan, en ese primer momento, repercusiones en los internautas puesto que se difuminan en la efímera duración de 24 horas de la story de Instagram sin que se generen repercusiones en las redes sociales, ni tampoco en los medios masivos. Es recién el 18 de noviembre el día en el que la historia del cierre del local de ropa "Chocolate" y los mensajes que por WhatsApp le dejaron las empleadas a Fernández de Kirchner vuelve al espacio público. Ese día la ex presidenta realiza una intervención en el foro mundial de Pensamiento 
Crítico CLACSO 2018, que es transmitida en directo por canales de aire y cable, y al final de su exposición vuelve a contar esta historia, usando las mismas palabras que aparecían en la story de Instagram y muestra que tiene puesta la camisa que le regalaron las mujeres. En este punto, en la intervención televisada y transmitida también online por las redes sociales, la camisa "transpirada" por la expresidenta se transforma en una prueba de la crisis económica del gobierno de Macri, dado que materializaba el cierre de fábricas y PYMES. En este sentido, si se toma como discurso de origen (D1), discurso en el cual se materializa, el caso se hace público (Carlón, 2015), la story de Instagram; se puede concluir en que se generó un movimiento de "circulación ascendente" al alcanzar los medios tradicionales en la transmisión del acto de Ferro y con sus repercusiones posteriores en la prensa gráfica. El caso de la camisa regalada por las empleadas de Chocolate alcanzó la televisión y redes sociales -durante la transmisión-; y el resto de los medios masivos de comunicación y los movimientos de internautas que replicaron la historia -con posterioridad al acto-. Es decir, la publicación en Instagram luego de la transmisión bajo el dispositivo del directo televisivo, en la cual la senadora contó la historia de las empleadas de la fábrica de ropa y mostró la camisa regalada -transpirada por el calor que hacía en el lugar del desarrollo del evento, descendió nuevamente a las redes sociales kirchneristas puesto que los internautas se apropiaron del discurso, lo viralizaron, lo intervinieron, lo compartieron, etc. En este punto, el análisis permite concluir que se genera una enunciación en primera persona, no obstante, es una enunciación institucional y política dado que se ponen en juego motivos temáticos vinculados a lo público y la mirada es desde el lugar de Fernández de Kirchner como opositora al gobierno nacional. Asimismo, el análisis permite concluir que la story que se genera desde la cuenta oficial de la expresidenta no genera repercusiones en otros espacios digitales, ni asciende al espacio de los medios masivos tradicionales en un primer momento. Es en la articulación del discurso político digital con el espacio urbano y la transmisión bajo el dispositivo del directo televisivo y en el vivo de las redes sociales, la que genera las repercusiones y los movimientos intersistémicos.

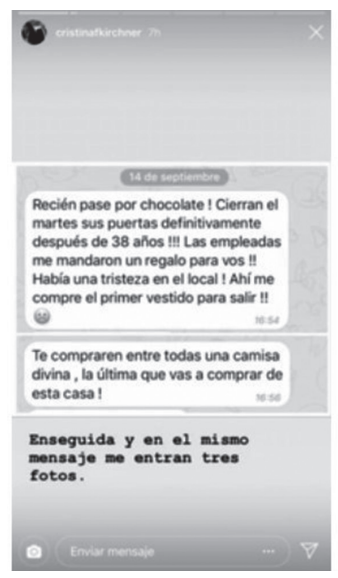

Figura 2. Story emitida desde la cuenta de Instagram de Cristina Fernández de Kirchner. Fuente: Instagram. 
En el caso de la cuenta de instagram de Macri, es preciso resaltar que, en el mismo período observado, se registran diferencias tanto en la enunciación que se desprende de las stories y publicaciones, como en su circulación hipermediática posterior.

En primer lugar, el análisis de la cuenta en Instagram durante el 2018 reveló que hay tanto publicaciones que retoman motivos temáticos vinculados a lo público, como a lo privado puesto que se muestra a Macri tanto en su rol de presidente como en su vida mundana. En relación con este último aspecto, se reponen "retazos de lo privado y de lo íntimo", tales como imágenes con su mujer Juliana Awada o con su hija Antonia. En efecto, es en paralelo al entramado de lo público-privado que se ha observado que caracterizó las cuentas oficiales de Macri en Facebook y Twitter desde su inicio. También en Instagram aparecen fotos que son del "álbum familiar" y otras que corresponden a las "fotos oficiales" del mandatario, con otros presidentes, en celebraciones nacionales, en conferencias de prensa televisivas, etc. Por consiguiente, Macri aparece representado en esta red social tanto como presidente como "hombre común".

Asimismo, y al igual que lo que hemos mencionado en el Facebook de Macri en períodos anteriores -electorales y no electorales-, en el 2018 también emergen fragmentos que reponen aspectos de lo íntimo y de lo privado del ciudadano, a través de fragmentos audiovisuales de timbreos y visitas a personas que le enviaron una carta al presidente.

Dentro del corpus analizado de stories y publicaciones, cabe observar que tanto las stories que describen actos oficiales como las que relatan la visita del presidente a un ciudadano que le envió una carta contando su historia, poseen operaciones de "apropiación" e "intervención". Se trata de operaciones -habilitadas por las opciones de la red social- que subrayan de qué día de la semana se trata y el lugar físico en el que transcurre la actividad. No obstante, el modo de armado de las stories presidenciales, implica una operación de "emulación de un video amateur", un tipo de operación que se ha registrado en Facebook en las conversaciones telefónicas del presidente con vecinos (Slimovich, 2016). A pesar de que se trata de videos registrados por el equipo presidencial, las tomas están realizadas con un celular y no parecen estar editadas.

Luego de la publicación de la story de Instagram, y dado que su duración es efímera en esa red social - está online por 24 hs., el video se comparte en el Facebook del presidente, primero como story y luego como publicación, quedando fijo en el Muro. A diferencia de las stories de Instagram, la operación de apropiación del contenido de Instagram y su pasaje a Facebook, implica una reducción puesto que tienden a ser más breves los videos subidos a Facebook y, asimismo, no poseen los textos redundantes de espacio y tiempo; por consiguiente, se trata de videos menos intervenidos que los de Instagram (ver la imagen 3, Macri, 2018a y la imagen 4, Macri, 2018b). Asimismo, también se concluye que hay una operación de interrelación mediática y de divergencia de discursividades políticas digitales que fluyen en las distintas redes sociales y medios. Si en el caso de Fernández de Kirchner, se registraban modos de la interfaz digital que implicaban una emulación del discurso periodístico y el hecho de compartir contenidos provenientes de los medios masivos, en el caso de la cuenta de Instagram de Macri en 2018, no se observa la existencia de contenidos de los medios masivos; no obstante, si se registra la emulación de lógicas de los medios tradicionales. 

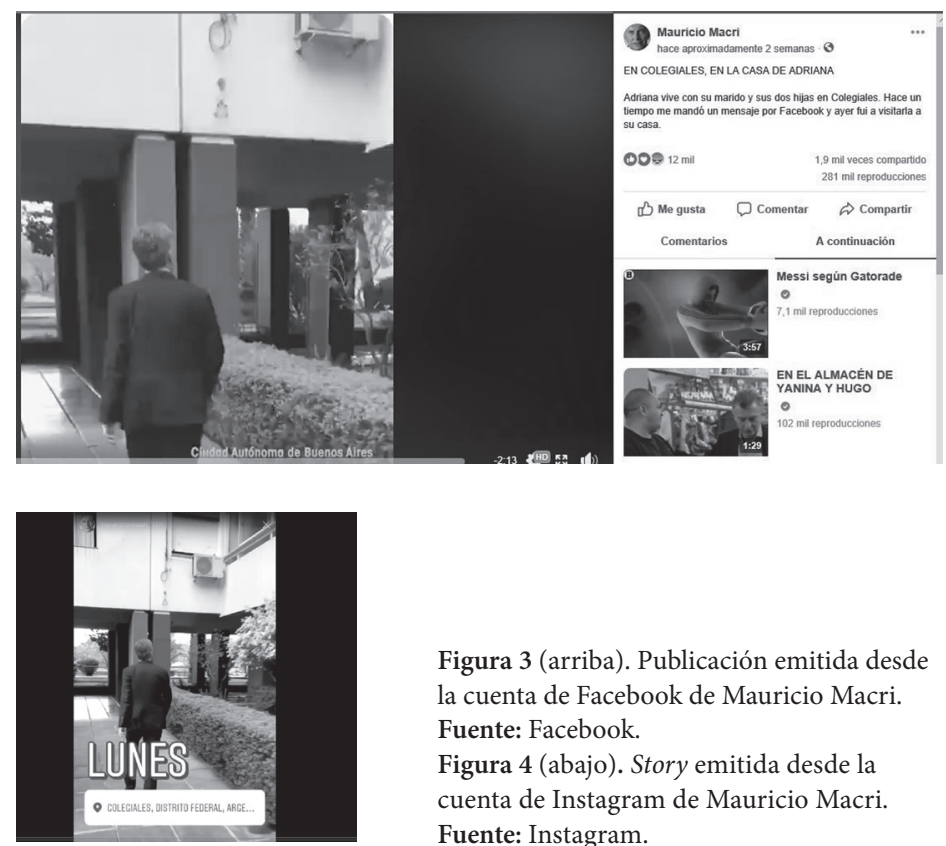

Figura 3 (arriba). Publicación emitida desde la cuenta de Facebook de Mauricio Macri. Fuente: Facebook. Figura 4 (abajo). Story emitida desde la cuenta de Instagram de Mauricio Macri. Fuente: Instagram.

Párrafo aparte merece el tipo de fotografía que predomina en la cuenta del entonces presidente. En las stories que relatan visitas de Macri a hogares de ciudadanos -o empresaspredominan las fotos que muestran al presidente con vecinos que se sacan selfies con sus teléfonos. En otras palabras, hay "fotos de selfies con el presidente", son "fotos de la selfie". No se registran imágenes en las cuales sea el propio presidente el que tome la foto. No hay selfies en la cuenta de Macri -ni tampoco en la de Fernández de Kirchner-. La ausencia de selfies, la existencia de videos en los cuales se lo ve a Macri de espaldas -evidenciando que hay otra persona sosteniendo el celular-, genera el efecto de un punto de vista profesional por sobre el político. Es decir, a pesar de la existencia de operaciones que emulan al internauta común -como la imitación de videos amateurs- predomina la enunciación del asesor por sobre la individual.

Asimismo, y a diferencia de lo que se observó en el caso de Fernández de Kirchner, en el corpus analizado también se registra la utilización por parte de Macri de "el vivo" de Instagram. Lo usó tanto para conversar en directo con algunos ciudadanos por teléfono, así como para responder a las consultas que le habían dejado con anterioridad en la cuenta de Instagram los internautas ciudadanos. Uno de los casos es la transmisión que se realizó en simultaneidad con el desarrollo del evento -en vivo- el 18 de julio de 2018. Un día antes Macri había realizado una conferencia de prensa televisiva en la cual había 
respondido preguntas de los periodistas, evidenciando una estrategia de diversificación -periodistas por la televisión y ciudadanos por las redes sociales-. En la transmisión en vivo del 18 de julio, Macri contestó preguntas de los ciudadanos que estaban anotadas en un papel -que habían dejado en su cuenta con anterioridad-y esa emisión se caracterizó por responder preguntas de la vida privada: “¿cómo la conoció a Juliana?”, ¿cuál fue su primer auto?, ¿qué hace en su tiempo libre?, entre otros de las consultas que le hicieron -el día anterior había respondido preguntas más vinculadas a su gestión pública-. Al mismo tiempo que transcurría el vivo en Instagram, los internautas ciudadanos, usuarios de la red social, dialogaban sobre temas políticos a través de comentarios a ese vivo en el medio de emojis en la pantalla del celular (Slimovich, 2018b). En este punto, cabe destacar que, por la propia configuración de la red social, el internauta que visualiza el vivo presidencial, puede optar por visualizar los comentarios en simultaneo de los usuarios de Instagram, en los cuales hay internautas "seguidores", "opositores" e "indecisos" (Slimovich, 2012) y se imponen los temas privados e íntimos sobre lo público/político.

Párrafo aparte merece la construcción del cuerpo presidencial en el vivo de Instagram. En la imagen se ven ciertas ojeras en Macri y un hablar, por momentos, cansino. En este punto, cabe especificar que Verón (1987c) conceptualiza el cuerpo presidencial como socializado y mediatizado: se construye sobre anulaciones y prohibiciones, e implica esa exhibición suficientemente distinguida como para que no se vea. En efecto, se trata de un metacuerpo lo que se expone en el vivo de Instagram del presidente. Construir un cuerpo presidencial en Instagram no es entonces mostrarse honesto, sino poner en escena la honestidad, en otro nivel. Los ciudadanos ven la transmisión, y quizás, por primera vez en la historia de la mediatización, producen discursos políticos que alcanzan el espacio público, en función de esa visualización y en simultaneidad con ella, a través de los comentarios de la red social. Este tipo de enunciación si bien pone en escena aspecto de lo corporal -como las ojeras o el aspecto cansado del presidente al hablar- repone una enunciación del asesor porque es la mirada otra la que comparte y graba sosteniendo el teléfono ese cuerpo presidencial, y no es el propio presidente, a nivel individual, el que sostiene el teléfono y emula el internauta ciudadano amateur.

Asimismo, también se registran "micro-argumentaciones lógicas" entre las publicaciones de Instagram. Se trata de "micro-entimemas" y "micro-ejemplos" que apuntan a mostrar que su gobierno está en "el buen camino". El kirchnerismo aparece como "contra-destinatario". A pesar de que el presidente da conferencias de prensa y es citado y replicado su discurso en los medios masivos, no hay en el instagram operaciones de apropiación del contenido de los medios tradicionales. En este punto se observa una diferencia con el corpus analizado de Fernández de Kirchner que sí comparte contenidos de los medios tradicionales - muchas veces para construir contra-argumentaciones-.

\section{Discusión}

El estudio de las cuentas de los diputados españoles en Instagram mostró, al igual que el nuestro, que los políticos tienden a compartir fotos tomadas por terceras personas antes 
que selfies. "Incluso dentro de las publicaciones en las que el diputado aparece solo, únicamente el 14,58\% son selfies" (Selva-Ruiz y Caro-Castaño, 2017, p. 911).

En este sentido, se puede concluir que las discursividades de los políticos en Instagram tienden a usar mucho menos selfies que las cuentas de instagrameros, influencers o usuarios comunes de la red social. No obstante, si los teóricos españoles asocian esta ausencia de selfies con un desaprovechamiento de las potencialidades de las redes sociales; y aúnan la selfie a la retórica de la espontaneidad; por el contrario, en esta investigación se concluye que la autofoto implica la anulación de la enunciación del asesor y la puesta en escena de una enunciación individual, difícil de articular con la "enunciación presidencial". La selfie implica una enunciación directa del político y su efecto en ese sentido es potente. En el caso de Macri, se observa la existencia de sólo dos videos tomados por el propio presidente en modo de selfie, por consiguiente, hay un brazo que no se ve en la imagen en ningún momento. Uno es el que grabó el 28 de noviembre, unos días antes de la celebración del G20 en la ciudad de Buenos Aires y en el que se pone en escena su rol como presidente de la Cumbre de Líderes Mundiales. El otro es el 3 de agosto de 2018. En este caso, cuando se analiza el discurso audiovisual, se trata de la entrada de él en la Casa Rosada, el saludo a los gendarmes y a los visitantes -niños- que se encontraban en el lugar. Es decir, la selfie se ubica en el espacio de la institución política: la casa de gobierno y retoma motivos temáticos vinculados a lo público. No se registra ninguna autofoto ni video grabado por el propio presidente que replique contenidos vinculados a lo privado o lo íntimo.

Si se retoma la teoría de la mediatización del cuerpo presidencial veroniana, se puede concluir que el cuerpo presidencial es un metacuerpo que no funciona en la creencia sino en la distancia con el ciudadano. Cuando emerge la selfie, el cuerpo del político y el del ciudadano se acercan. En este caso, aunque se trata de videos tomados en la mano por el propio presidente, la enunciación por definición es institucional y en ese punto se genera, igual, la distancia.

El estudio de los diputados españoles mostró una predominancia a "mostrar al político en el ejercicio de sus funciones en la vida pública en Instagram" (Selva-Ruiz y Caro-Castaño, 2017: 913), en consonancia con estudios de otros países de la democracia occidental.

Por un lado, en el caso de la senadora y expresidenta, efectivamente se evidencia una construcción a partir de las stories del ejercicio de sus funciones como senadora. Se la visualiza en la banca del senado en muchas publicaciones de debates importantes acontecidos durante el año. También, se registran publicaciones en Instagram que son fragmentos de videos en los cuales se puede escuchar cuál ha sido su intervención en el senado. Asimismo, y en consonancia con la predominancia de las discursividades políticas digitales, y con el modo de comunicar en las redes que ha sido característico de Fernández de Kirchner desde su inicio, se observa la existencia de micro-argumentaciones lógicas que apuntan a demostrar el fracaso de la gestión macrista en el poder y de realizar un balance del presente y una reconfiguración del pasado en el que ella y su marido Néstor Kirchner gobernaron el país. En este sentido, se configura un contra-destinatario macrista (propio del discurso político), se interpela al internauta indeciso a través de las argumentaciones breves y pildorizadas y emergen el componente descriptivo y prescriptivo del discurso político (Verón, 1987b). 
Por otro lado, en el caso de Macri, sí se evidencian fotos que muestran al presidente inmerso en su vida privada e íntima, con su hija, fotos de su hija sola, de él descansando con su mujer y familia, etc., en sintonía con el entramado de lo público-privado que aparece en las redes sociales macristas desde la apertura de sus cuentas. Es en este sentido, que, desde Instagram, al igual que en Facebook y Twitter, se muestran aspectos del hombre común que habita el cuerpo presidencial (Slimovich, 2017b). Por otro lado, se interpela a un contra-destinatario kirchnerista a través de las argumentaciones breves en forma de texto que se comparten en las publicaciones. Es decir, en la cuenta de Instagram de Macri analizada, en el año no electoral, se evidencia una mixtura público-privado que ha caracterizado sus otras redes sociales -Facebook y Twitter- desde el inicio.

\section{Conclusiones}

Luego del análisis realizado desde la socio-semiótico, desde la teoría de la mediatización (Verón, 1986, 1987b) y desde el dispositivo analítico de circulación hipermediática (Carlón, 2015), se concluye en determinar la existencia de dos modos diferentes de construir la enunciación política y dos tipos de movimientos comunicacionales de las publicaciones y stories surgidas desde la institución política en Instagram.

Por un lado, en el caso de Fernández de Kirchner, tanto en las stories como en las publicaciones, se habla en primera persona; no obstante, se trata de una "enunciación político/ institucional". Se convocan motivos vinculados a lo público, a su rol como opositora, como senadora y a su pasado como expresidenta. No aparecen autofotos ni rasgos que evoquen un punto de vista extrainstitucional en el armado de los videos. No hay una puesta en escena de aspectos de lo mundano. Cuando aparecen referencias a lo familiar, a lo privado, a lo íntimo, a su condición de "mujer" están puestas en correlación con la vida pública de la senadora, y con su posicionamiento de oposición al gobierno nacional. Además, las fotos que se publican en su cuenta de Instagram son siempre tomadas por terceros poniendo en escena la enunciación del asesor/profesional.

Por otro lado, el análisis del tipo de discursividad puesta en juego en la cuenta oficial de Instagram del entonces presidente argentino, mostró la puesta en escena de una "enunciación político/institucional", de modo paralelo a lo especificado con Fernández de Kirchner. No obstante, dado que emergen discursividades que dan cuenta de lo mundano del presidente, de su rol como esposo, padre, hombre, amo de casa, hacedor de ejercicios matutinos, individuo cansado de las jornadas largas laborales, etc. cabe destacar una diferencia. En la cuenta de Instagram de Macri hay marcas de la "enunciación individual/ extrainstitucional" - y en este punto es una invariante de las redes sociales de Macri a diferencia de las de Fernández de Kirchner. No obstante, estas marcas de lo individual/ extrainsitucional quedan difuminadas por la puesta en escena de la mirada otra, la del asesor/profesional. Al tratarse de un punto de vista de un tercero (el que sostiene el teléfono y saca la foto), aunque se plasmen imágenes del álbum familiar, y aunque se emule la foto espontánea y la amateur en su calidad, tienden a insertarse en una enunciación que conjuga lo político/institucional, lo individual y la mirada del asesor/administrador de gobierno. 
Asimismo, cabe concluir que en las stories y publicaciones de Macri en Instagram, al igual que en las otras redes sociales macristas, se interpela a un internauta "voyeur" de lo íntimo, tanto de la vida de Macri como de la del ciudadano común al que visita el presidente. Al tratarse de stories que se publican diariamente y que tienen una vida efímera en la web, se interpela también a un internauta que visita regularmente las redes sociales del presidente.

Por último, es preciso marcar las diferencias en los movimientos comunicacionales. En el caso de los discursos de Macri emitidos desde la cuenta de Instagram, los que generan movimientos comunicacionales ascendentes, es decir, los que alcanzan los medios masivos de comunicación y continúan con saltos hipermediáticos con las reacciones de los internautas ciudadanos, son las publicaciones en Instagram que están en relación con grandes acontecimientos político-mediáticos, o las transmisiones en vivo por la red social. Como se ha mencionado con anterioridad, estas discursividades implican una interacción del discurso institucional en Instagram a través de la imagen emitida, discursos que se plasman en los celulares con la función que implica la visualización de comentarios de Instagram y la operación de compartir, apropiarse, intervenirlo, etc. que realiza el internauta visualizador del vivo.

Por el contrario, en el caso de Fernández de Kirchner los cambios de escala de la mediatización de su discurso tienden a generarse cuando, además de emitirse stories y publicaciones en Instagram, se generan articulaciones en el espacio urbano en actos políticos, $\mathrm{y}$, por consiguiente, son transmitidos también por la televisión y por el vivo de las redes sociales.

\section{Notas}

1. El partido Propuesta Republicana (PRO) fue fundado en 2002 alrededor de la figura de Mauricio Macri, y reclutó dirigentes de la derecha argentina, de los partidos mayoritarios (el peronismo y el radicalismo) y también de la sociedad civil -empresas, ONG y think thank- (Vommaro y Morresi, 2014; Canelo 2019). Luego de ocho años a cargo de la ciudad de Buenos Aires, Macri es elegido presidente de la Argentina y "convirtiéndose en el primer presidente argentino desde la transición a la democracia que no proviene ni del Partido Justicialista ni de la UCR" (Tagina, 2018:35). En octubre de 2019 fue elegido presidente Alberto Fernández y vicepresidenta Cristina Fernández de Kirchner, implicando el regreso del peronismo al gobierno nacional y "el fin de la construcción mediática del éxito" en las redes sociales de los líderes de Juntos por el Cambio.

2. Annunziata, Ariza y March (2018) sostienen que este tipo de estrategias se despliegan en las campañas del PRO desde 2007 y que en el 2017 en los espacios digitales de Macri y María Eugenia Vidal el contenido que predomina justamente es el de proximidad.

3. Los datos de las cuentas de Instagram de Mauricio Macri y Fernández de Kirchner fueron capturados en enero de 2020. 


\section{Bibliografía}

Annunziata, R. (2012). ¿ Hacia un nuevo modelo de lazo representativo? La representación de proximidad en las campañas electorales de 2009 y 2011 en Argentina. En Cheresky, I. y Annunziata, R. Sin programa, sin promesa. Liderazgos y procesos electorales en Argentina (pp. 45-87). Buenos Aires: Prometeo.

Annunziata, R., Ariza, A. Fernanda y March, V. (2018). “Gobernar es estar cerca”. Las estrategias de proximidad en el uso de las redes sociales de Mauricio Macri y María Eugenia Vidal. En Revista mexicana de opinión pública, (24), 71-93. Disponible en: https://dx.doi. org/10.22201/fcpys.24484911e.2018.24.61520

Barthes, R. (1985). La aventura semiológica. Barcelona: Paidós.

Beas, D. (2011). La reinvención de la política. Internet y la nueva esfera pública. Buenos Aires: Planeta.

Bossetta, M. (2018). The Digital Architecture of Social Media: Comparing Political Campaigning on Facebook, Twitter, Instagram and Snapachat in the 2016 U.S. Election. Journalism \& Mass Communication Quarterly 2018 95(2), 471-496.

Canelo, P. (2019). ¿Cambiamos? La batalla cultural por el sentido común de los argentinos. Buenos Aires: Siglo veintiuno.

Carlón, M. (2014). ¿Del arte contemporáneo a una era contemporánea? En Reviglio, M.C. y Rovetto, F. (comps.). CIM. Estado actual de las investigaciones sobre mediatizaciones (pp. 24-41). Rosario: UNR Editora. Disponible en: http://www.cim.unr.edu.ar/archivos/ cuadernodelcim2.pdf

Carlón, M. (2015). Público, privado e íntimo: el caso Chicas bondi y el conflicto entre derecho a la imagen y libertad de expresión en la circulación contemporánea. En Castro, P. C. (org.), Dicotomia público/privado: estamos no caminho certo? (pp. 211-232). Maceió: EDUFA.

Carlón, M. (2016a). Apropiación contemporánea de la teoría comunicacional de Eliseo Verón. In E. Vizer y C. Vidales (Coords.), Comunicación, campo(s) teorías y problemas. Una perspectiva Internacional (pp. 125-153). Barcelona: Editorial Comunicación Social.

Carlón, M. (2016b). Registrar, subir, comentar, compartir: prácticas fotográficas en la era contemporánea. En Corro, P. y Robles, C. (eds.). Estética, medios y subjetividades. Santiago: Universidad Pontificia Católica de Chile.

Carlón, M. (2018). Bajo el signo del presentismo: mediatización, cultura y sociedad contemporánea. En J. Ferreira et al (Orgs.), Entre o que se diz e o que se pensa: onde está a mediatizacao - I Seminario internacional de Pesquisas em Midiatizacoes e procesos sociais (pp. 103-138). UNISINOS. Disponible en: http://midiaticom.org/files/entreoquesedizeoquesepensa.html?fbclid=IwAR18N2zpY9U_xaVHN7ofE4yS9zrStIEYVrXBSpPssUBxyDacUpb8nH3-Oc0\#page $=5$ \&zoom $=\mathrm{z}$

Carlón, M. y Scolari, C. (Eds.). (2009). El fin de los medios masivos. El comienzo de un debate. Buenos Aires: La Crujía.

Castells, M. (2009). Comunicación y poder. Madrid: Alianza Editorial.

Cheresky, I. (2015). El nuevo rostro de la democracia. Buenos Aires: Fondo de Cultura Económica. 
Cheresky, I. (2019). Soberanía ciudadana y presidentes en busca de hegemonía. Buenos Aires: Prometeo.

D’Adamo, O., y García Beaudoux, V. (2013). Storytelling y comunicación política: el valor de un relato bien. En Crespo, I. y Del Rey, J. (eds.). Comunicación política y campañas electorales en América Latina (pp. 55-68). Buenos Aires: Biblos.

Dader, J. (2003). Ciberdemocracia y comunicación política virtual: el futuro de la ciudadanía electrónica tras la era de la televisión. En Berrocal, S. (coord.), Comunicación política en televisión y nuevos medios (pp. 309-342). Barcelona: Ariel.

Fernández de Kirchner, C. [Cristina]. (3 de julio de 2018). Todo empezó con dos pizzas [Story de Instagram].

Fernández de Kirchner, C. [Cristina]. (15 de septiembre de 2018). Ayer al aterrizar en Calafate [Story de Instagram].

Gallardo, B. y Enguix, O. (2016). Pseudopolítica: el discurso político en las redes sociales. Valencia: Universitat de Valencia.

García Beaudoux, V.; D’Adamo, O. y Slavinsky, G. (2005). Comunicación política y campañas electorales. Estrategias en elecciones presidenciales. Barcelona: Gedisa.

Gindin, I. L. (2018). “Sorry. ¿Sabés qué?”: proximidad y ethos íntimo en @CFKArgentina. Icono 14, 16 (1), pp. 114-135.

Jung, Y., Tay, A., Hong, T., Ho, J., Goh, Y. (2017). Politician's strategic impression management on Instagram. Proceedings of the 50th Hawaii intl conf on system sciences, pp. 2195-2201. Disponible en: http://hdl.handle.net/10125/41420

López Rabadán, P. y Doménech- Fabregat, H. (2018). Instagram y la espectacularización de las crisis políticas. Las $5 \mathrm{w}$ de la imagen digital en el proceso independentista de Cataluña. En El profesional de la información, septiembre-octubre, 27, N5. Recuperado de http:// www.elprofesionaldelainformacion.com/contenidos/2018/sep/06.html

Macri, M. [Mauricio]. (25 de julio de 2018). En colegiales en la casa de Adriana. [Actualización del estado en Facebook]. Disponible en: https://www.facebook.com/mauriciomacri/ videos/en-colegiales-en-la-casa-de-adrianaadriana-vive-con-su-marido-y-sus-dos-hijas en/10156594017183478/

Macri, M. [Mauricio]. (25 de julio de 2018). Lunes. Colegiales. [Story de Instagram].

Manin, B. (1998). Los principios del gobierno representativo. Madrid: Alianza.

Manovich, L. (2017). Instagram and contemporary image. California Institute for Telecommunication and Information \& The Graduate Center, City University of New York (CUNY), Cultural Analytics Lab. Disponible en: http://manovich.net/index.php/projects/ instagram-and-contemporary-image.

Ministerio de Cultura. Presidencia de la Nación. (2019). Informe general de la Encuesta Nacional de Consumos Culturales 2017. Disponible en: https://www.cultura.gob.ar/ nueva-encuesta-de-consumos-culturales_5682/

Mitchelstein, E.; Leiva, S.; Giuliano, C. y Boczkowski, P. J. (2018). La política da que hablar: Engagement en medios y redes sociales. CIC. Cuadernos de información y comunicación, 23: pp. 157-173. Disponible en: http://revistas.ucm.es/index.php/CIYC/article/viewFile/60913/4564456547638 
Mohamed, S. (2019). Instagram and Political Storytelling among Malaysian Politicians during the 14th general Election. En Journal Komunikasi: Malaysian Journal of Communication, Jilid 35 (3): pp. 353-371.

Novaro, M. (1994). Pilotos de tormenta: crisis de representación y personalización de la política en la Argentina (1989-1993). Buenos Aires: Letra Buena.

Olof Larsson, A. (2019). Skiing all the way to the polls: Exploring the popularity of personalized posts on political Instagram accounts. Convergence: The International Journal of Research into New Media Technologies 2019 25(5-6), pp. 1096-1110.

Quevedo-Redondo. R. y Portales-Oliva, M. (2017). Imagen y comunicación política en Instagram. Celebrificación de los candidatos a la presidencia del gobierno. El profesional de la información, septiembre-octubre, 26 (5) Disponible en: http://www.elprofesionaldelainformacion.com/contenidos/2017/sep/index.html

Rosanvallon, P. (2009). La legitimidad democrática: Imparcialidad, reflexividad, proximidad. Buenos Aires: Manantial.

Segre, C. (1985). Tema / motivo. En Principios de análisis del texto literario. Barcelona: Crítica.

Selva-Ruiz, D. y Caro-Castaño, L. (2017). Uso de Instagram como medio de comunicación política por parte de los diputados españoles: la estrategia de humanización en la "vieja" y la "nueva" política. El Profesional de la Información 26 (5), 903-915.

Slimovich, A. (2012). El Facebook de los gobernantes. El caso de Cristina Fernández de Kirchner y de Mauricio Macri. En Carlón, M. y Fausto Neto, A. (Comps.). Las políticas de los internautas. Nuevas formas de participación (pp. 137-154). Buenos Aires: La Crujía.

Slimovich, A. (2014). El discurso macrista en Twitter: un análisis sobre la campaña para la reelección del jefe de gobierno de Buenos Aires. Revista de Estudios Políticos y Estratégicos 2(1),8-27. Disponible en: http://revistaepe.blogutem.cl/files/2014/07/03_Rev_estudios_ politicos_estrategicos_vol2_n1_2014_Ana_S_Discurso_Macrista_8-27.pdf

Slimovich, A. (2016). La interfaz entre lo político y lo informativo en la mediatización televisiva y las redes sociales en las campañas argentinas de 2009 y 2011 (tesis doctoral inédita). Facultad de Ciencias Sociales de la Universidad de Buenos Aires, Buenos Aires.

Slimovich, A. (2017a). La ruta digital a la presidencia argentina. Un análisis político e hipermediático de los discursos de Mauricio Macri en las redes sociales. Dixit 26, (24-43). Disponible en: https://revistas.ucu.edu.uy/index.php/revistadixit/article/view/1321/1369 Slimovich, A. (2017b). Discursos políticos para todos y todas. Reflexiones sobre las redes sociales del presidente argentino. Redes y Trolls. Sociales en debate 12 (pp. 37-48). Octubre 2017. Publicación de la Facultad de Ciencias Sociales de la Universidad de Buenos Aires. ISBN: 978-950-29-1332-2. Disponible en: http://www.sociales.uba.ar/wp-content/blogs. dir/219/files/2017/10/discursospol-ANA-SLIMOVICHv2.pdf

Slimovich, A. (2018a). \#TinelliMercenarioK. La mediatización del Presidente argentino y los trolls macristas. InMediaciones de la Comunicación 13(1), 159-186. Facultad de Comunicación y Diseño Gráfico de la Universidad ORT, Uruguay. Disponible en: https:// revistas.ort.edu.uy/inmediaciones-de-la-comunicacion/article/view/2830/2823

Slimovich, A. (2018b). La política en Instagram. El metacuerpo presidencial: los internautas ciudadanos, seguidores y opositores. En Bordes. Revista de Política, Derecho y Sociedad. Universidad Nacional de José C Paz. Disponible en: http://revistabordes.com.ar/lapolitica-en-instagram/ 
Slimovich, A. (2019). La mediatización contemporánea de la política en Instagram. Un análisis desde la circulación hipermediática de los discursos de los candidatos argentinos. Revista Sociedad, №39 (noviembre 2019 a abril 2020), 31-45. Facultad de Ciencias Sociales. Universidad de Buenos Aires. ISSN: 2618-3137. Disponible en: https://publicaciones. sociales.uba.ar/index.php/revistasociedad/article/view/5088/4222

Steimberg, O. (1993a [1982]). Utopías periodísticas: el uno, el otro y el espejo. Medios y Comunicación 20, Buenos Aires.

Tagina, M. L. (2018). Argentina, kirchnerismo y después: la alternancia electoral de 2015. En Alcantará, M.; Buquet, D. y Tagina, M. (eds.), Elecciones y partidos en América Latina en el cambio de ciclo. Madrid: Centro de Investigaciones sociológicas.

Van Aelst, P., Scheafer, T. y Stanyer, J. (2011). The personalization of Mediated Political Communication: a review of Concepts, Operationalizations and key findings. Journalism 13, 203.

Verón, E. (2011 [2007]). La televisión, ese fenómeno "masivo" que conocimos, está condenada a desaparecer. Entrevista a Eliseo Verón. Letra. Imagen. Sonido: Ciudad Mediatizada, 6-7, pp.31-40. Disponible en: http://www.revistalis.com.ar/index.php/lis/article/ view/86/85

Verón, E. (2001). El cuerpo de las imágenes. Buenos Aires: Norma.

Verón, E. (1998 [1995]). Mediatización de lo político. Estrategias, actores y construcción de los colectivos. En Gauthier, G.; Gosselin A. y Mouchon, J. (comps.). Comunicación y Política (pp. 220-236). Barcelona: Gedisa.

Verón, E. (1987a). La semiosis social. Barcelona: Gedisa.

Verón, E. (1987b). La palabra adversativa. Observaciones sobre la enunciación política. En El discurso político. Lenguajes y acontecimientos. Buenos Aires: Hachette.

Verón E. (1987c). Cuerpo y metacuerpo en Democracia Audiovisual. Après, 293-294, Paris, pp. 32-35.

Verón, E. (1986). La mediatización. Buenos Aires: Facultad de Filosofía y Letras. Universidad de Buenos Aires.

Verón, J. y Pallarés, S. (2017). La imagen del político como estrategia electoral: el caso de Albert Rivera en Instagram. Mediatika16, pp.195-217.

Vommaro, G. Morresi, S. y Belloti, A. (2015). Mundo PRO. Un partido fabricado para ganar. Buenos Aires: Planeta.

Vommaro, G. y Morresi, S. (2014). Unidos y diversificados: la construcción del partido PRO en la CABA. Revista SAAP, 8(2), 375-417. Disponible en: http://www.scielo.org. ar/scielo.php?script=sci_arttext\&pid=S1853-19702014000200002\&lng=es\&tlng=es.

\footnotetext{
Abstract: From sociosemiotics, the theory of the mediatization of politics and the analytical device of contemporary circulation was investigated in publications and stories published on Instagram in the official accounts of Argentine former President, Mauricio Macri, and the vicepresident, and former president, Cristina Fernández de Kirchner, between March and December 2018. It was concluded in the configuration of two different
} 
enunciative strategies that put into play the political / institutional, the individual and the assessor's gaze; as well as two types of communicational movements and changes of scale in mediatization.

Keywords: mediatization - politics - Instagram - social networks - macrismo - kirchnerismo - circulation.

Resumo: A partir da socioemiótica, a teoria da midiatização da política e o dispositivo analítico da circulação contemporânea foram investigados nas publicações e histórias publicadas no Instagram nas contas oficiais do ex-presidente Mauricio Macri e do atual vice-presidente e ex-presidente Cristina Fernández de Kirchner, entre março e dezembro de 2018. Concluiu-se na configuração de duas estratégias enunciativas diferentes que colocam em jogo o olhar político / institucional, o indivíduo e o consultor; bem como dois tipos de movimentos comunicacionais e mudanças de escala na midiatização.

Palavras-chave: midiatização - política - Instagram - redes sociais - macrismo - kirchnerismo- circulação.

[Las traducciones de los abstracts fueron supervisadas por el autor de cada artículo] 
